\title{
Public Trust in Community Pharmacists in South Korea: A Survey Study
}

\author{
Sung Won Yoon ${ }^{1}$, Hye Sung Han ${ }^{1}$, Hae-Young Park ${ }^{2 *}$, and Hyun Soon Sohn ${ }^{1 *}$ \\ ${ }^{1}$ College of Pharmacy, CHA University, Gyeonggi-do 11160, Republic of Korea \\ ${ }^{2}$ BK21 FOUR Community-Based Intelligent Novel Drug Discovery Education Unit, College of Pharmacy and Research Institute of Pharmaceutical \\ Sciences, Kyungpook National University, Daegu 41566, Republic of Korea \\ (Received September 24, $2021 \cdot$ Revised November 30, $2021 \cdot$ Accepted December 2, 2021)
}

\begin{abstract}
Background: Trust is a key component for the good relationship between patients and healthcare professionals but trust for community pharmacists has not been studied much. Objectives: This study aimed to measure public trust in community pharmacists and to investigate variables that affect trust level in South Korea. Methods: A total of 25 questions, including 13-items for three dimensions of trust (pharmacists' behavior/attitude, technical competence, communication skills) and 1-item for overall trust were developed. The survey was conducted online and the data from 416 respondents were analyzed with a t-test, an ANOVA and a multiple linear regression analysis. Results: The average scores (mean \pm standard deviation) for the three dimensions of trust in community pharmacists were $3.47 \pm 1.05$ (out of 5 points) for pharmacists' behavior/attitude, $3.67 \pm 0.99$ for technical competence, and 3.66 \pm 0.99 for communication skills. The average of the 13 items incorporating all parameters was $3.56 \pm 1.02$ and the overall trust level was $7.16 \pm 1.62$ (out of 10 points). The total sum of the 13 items differed significantly by age group $(p=0.02)$ and frequency of pharmacy visits $(p=0.04)$. Each dimension had an independent impact on the trust level, and pharmacists' behavior/attitude had the greatest impact on trust levels. Conclusions: This study showed that pharmacists' behavior/attitude had the most significant impact on the trust level. However, the level of trust in pharmacists' behavior/attitude is not yet sufficiently satisfactory, and further improvements are required to increase trust in community pharmacists.

KEYWORDS: Trust in pharmacist, trust scale, constituents of trust, community pharmacist
\end{abstract}

Trust is the most important factor that essentially defines the relationship between healthcare providers and patients. Patients typically undergo treatment under specialized conditions that are characterized by uncertainty, risk, and interdependence in the medical field. Consequently, patients exhibit vulnerability and a dependence on healthcare professionals because of these features. Therefore, trust in healthcare professionals influences patients' willingness for treatment, sharing of personal information, and adherence to treatment plans. ${ }^{1-3)}$

Among healthcare providers, community pharmacy pharmacists are the professionals who contact patients most frequently through pharmaceutical care services such as drug dispensing, prescription reviews, and over-the-counter (OTC) sales in countries where drug prescribing and dispensing of medicines are functionally separated. ${ }^{4,5)}$ A good relationship between a patient and a pharmacist is known to have a direct impact on the patient's quality of life, and trust between the patient and pharmacist is the most influential aspect in establishing a good relationship. ${ }^{6-8)}$

According to a systematic literature review on patients' perspectives on community pharmacists in the United Kingdom, the levels of trust among patients differed depending on the type of community pharmacy service. ${ }^{9)}$ However, previous studies have commonly found that trust in pharmacists is essential in expanding pharmacy-led services. In a qualitative study, Gregory et al. reported that Canadian pharmacists can

\footnotetext{
*Correspondence to: Hae-Young Park, College of Pharmacy and Research Institute of Pharmaceutical Sciences, Kyungpook National University, Daegu 41566, Republic of Korea

Tel: +82-+82-53-950-8580, Fax: +82-53-950-8557, E-mail: hypark0303@gmail.com
} 
gain or lose the trust of patients depending on the behavior and attitude of pharmacists. Easy accessibility for patients and respect and acknowledgment from pharmacists were positive factors for establishing trust with patients. However, a commercial approach and lack of consistency or transparency can undermine trust between patients and pharmacists. ${ }^{10)}$

Scales evaluating patients' trust in pharmacists were not developed until 2006 and were first published in Thailand and Singapore. ${ }^{11,12)}$ In Thailand, Ngorsurches et al. developed a new scale that included 30 items measuring patients' trust in pharmacists through expert reviews and focus group discussions, which consisted of five main components: fidelity, competence, confidentiality, honesty, and global trust. ${ }^{11)}$ Furthermore, Zhang et al. developed a 12-item scale for measuring patients' trust in pharmacists in Singapore based on literature reviews and focus group discussions. ${ }^{12}$ In these studies, each item can be divided into three dimensions: benevolence, technical competence, and communication. Both scales were found to provide valid, efficient, and reliable measures of patients' trust in pharmacists.

Although many studies have previously assessed trust between patients and physicians among healthcare providers, a relatively small number of studies have investigated this parameter between pharmacists and patients. In fact, no such study has been published in South Korea.

Consequently, this study aimed to conduct a quantitative questionnaire survey to evaluate the general population's trust in community pharmacists and to investigate factors that can either enhance or undermine public trust in community pharmacists. Korean pharmacists, as with pharmacists from other countries, seek to expand patient-centered pharmaceutical care services beyond the simple administration or dispensation of medication. Therefore, the results of this study could serve as a basis for designing advanced community pharmacy services in South Korea and countries with similar healthcare systems.

\section{Methods}

\section{Survey questionnaire}

The design of this study comprised a cross-sectional questionnaire survey that consisted of a total of 25 questions, which were divided into four parts: Part A-D (Supplement Table S1). The questions in Part A aimed to identify whether the respondents were in-service pharmacists or students of pharmaceutical college-namely, ineligible subjects. Part B included three questions that surveyed the individual experiences of community pharmacy services over the past 1 year, the average number of visits to a community pharmacy per month, and the purpose of the visits. Part C consisted of 13 questions that examined the three dimensions of public trust in pharmacists, namely, behavior/attitude, technical competence, and communication skills, and 1 question regarding the overall trust in community pharmacists based on the respondents' experiences. Referring to the factors used in previous studies that have investigated public trust in physicians and pharmacists ${ }^{11-12)}$ and reflecting upon the South Korean healthcare system, the dimension of pharmacists' behavior/attitude included questions on fidelity, honesty, respect, ethics, confidentiality, and consideration for patients. Furthermore, the technical competence dimension contained questions concerning the pharmacological knowledge and professional skills of community pharmacists, whereas the communication skill dimension assessed the pharmacists' communication capability. Each dimension was measured using a 5-point Likert scale: 1 point (strongly disagree), 2 point (disagree), 3 point (neutral), 4 point (agree), and 5 point (strongly agree). The higher the end-result on this scale was, the greater level of trust that the respondents had for community pharmacists was. In addition, their overall trust in pharmacists was measured with a 10-point scale: from 1 point (do not trust at all) to 10 points (strongly trust). Finally, Part D comprised seven questions that collected sociodemographic information (i.e., the respondents' gender, age, level of education, residential area, number of close acquaintances who were pharmacists, perceived health status, and interest in health or health-related information). The responses for perceived health status and interest in health and health-related information were reclassified into positive and negative responses. Specifically, positive answers included very good/ very interested and good/interested; the other responses were considered negative answers. A pilot survey was initially conducted with experts and 10 subjects to ensure the accuracy and validity of the first draft of questionnaires. The questionnaire was finalized after reflecting on the feedback received through the pilot study.

\section{Subjects and survey administration}

This survey was conducted with people aged 20 or older. Incumbent pharmacists or prospective pharmacists (pharmacy students) whose opinions may have been biased or prejudiced 
were excluded from the survey because this study investigates the trust level in pharmacists from the perspective of the general public. The survey subjects were recruited by a convenient sampling method using the researchers' various human social network service networks, and the Google survey was conducted online. The purpose of this survey was explained to the participants at the beginning of the questionnaire, and those who understood it and responded to the survey were considered to have voluntarily agreed to participate in the study. Because all the respondents maintained their anonymity, as no sensitive personal information was collected, the review exemption was confirmed by the institutional review board of the principal investigator's institution (IRB No. 1044308-202002-HR-003-01).

\section{Data analysis}

The categorical variables related to the respondents' characteristics were presented as the number of respondents (N) and frequency (\%). The results of the 5-point Likert scale items were estimated via the mean and standard deviation (SD). The statistical significance was analyzed with a significance level of 0.05 by applying a t-test or one-way ANOVA to assess differences in the trust level with respect to the respondents' characteristics. A multiple linear regression analysis was performed to determine whether the three dimensions of the pharmacists' trust (behavior/attitude, technical competence, and communication skills) were suitable for assessing the overall trust of community pharmacists and how they affected the overall trust in pharmacists. Microsoft Excel 2019 was used for all the statistical analyses.

\section{Results}

\section{Characteristics of respondents}

In total, 430 respondents were initially enrolled; however, six in-service pharmacists or pharmacy students and eight respondents who had never visited a community pharmacy in the last 1 year were excluded. Of the 416 subjects included in the analysis, $229(55.0 \%)$ were male and $187(45.0 \%)$ were female (Table 1). Individuals aged 50-59 years comprised majority of the respondents $(33.7 \%)$, followed by the age groups of 20-29 years (24.3\%), 60-69 years (16.6\%), and 70 years and above (11.5\%). The number of respondents with an education level of college/university was the highest at 273 (65.6\%). Most were residents of a metropolitan area: 177
(42.5\%) lived in Seoul and 193 (46.4\%) lived in Gyeonggi/ Incheon. In terms of the frequency of visiting community pharmacies, 178 (42.8\%) had visited a community pharmacy once or less per month during the last 1 year and 145 (34.9\%) had visited 2-3 times per month. A total of 358 respondents $(86.1 \%)$ reported visiting community pharmacies within the past year to obtain prescription medication, which constituted the largest proportion. Furthermore, 233 (56.0\%) respondents indicated that they did not know of a pharmacist among their close acquaintances. Moreover, 182 (43.7\%) reported being in a positive health condition, whereas $49(11.7 \%)$ indicated poor or very poor health. Finally, 214 (51.4\%) expressed a positive interest in their health or health-related information, while 33 $(7.9 \%)$ implied a lack of interest or were disinterested in their health or health-related information.

\section{Trust level in community pharmacists}

The average scores (mean $\pm \mathrm{SD}$ ) for the three dimensions of trust, namely, behavior/attitude, technical competence, and communication skills were $3.47 \pm 1.05,3.67 \pm 0.99$, and $3.66 \pm 0.99$, respectively. The average of the 13 items incorporating all parameters measured was $3.56 \pm 1.02$ points (Table 2). Among the behavior/attitude items, the score for "Pharmacists will be honest with you if a mistake was made" was the lowest at 2.98 , followed by 3.17 points for "Pharmacists choose the best medicine for me instead of following their personal interests." For the technical competence-related items, the highest score was 3.95 for "Pharmacists have adequate expertise in medicine," and the lowest score was 3.47 for "Pharmacists thoroughly review the appropriateness of prescription drugs." The respondents gave the lowest score for "Pharmacists allow me to ask any pharmacy-related questions and provide a sincere answer" (3.42) among the questions related to communication skills (Table 2).

The overall trust level for community pharmacists was $7.16 \pm 1.62$ points in a 10 -point scale. Among the respondents, 117 (28.1\%) rated pharmacists with 8 points, and 102 (24.5\%) marked this trust with 7 points. Only $20(4.8 \%)$ responders gave 10 out of 10 points, while $64(15.3 \%)$ rated pharmacists with less than 5 points (Fig. 1).

\section{Trust level in pharmacists by respondent characteristics}

The average scores (mean $\pm \mathrm{SD}$ ) for the sums of the 13 items of the three dimensions were $46.30 \pm 9.39$. The sum of the 13 items significantly differed depending on the age group $(<50$ 
304 / Korean J Clin Pharm, Vol. 31, No. 4, 2021

Table 1. Characteristics of respondents

\begin{tabular}{|c|c|c|c|}
\hline \multicolumn{2}{|r|}{ Characteristics } & \multirow{2}{*}{$\frac{N}{416}$} & \multirow{2}{*}{$\begin{array}{r}\% \\
100.0\end{array}$} \\
\hline Total number of res & & & \\
\hline \multicolumn{4}{|c|}{ Sociodemographic aspects } \\
\hline \multirow{2}{*}{ Gender } & Male & 229 & 55.0 \\
\hline & Female & 187 & 45.0 \\
\hline \multirow{6}{*}{ Age group (years) } & $20-29$ & 101 & 24.3 \\
\hline & $30-39$ & 33 & 7.9 \\
\hline & $40-49$ & 25 & 6.0 \\
\hline & $50-59$ & 140 & 33.7 \\
\hline & $60-69$ & 69 & 16.6 \\
\hline & $\geq 70$ & 48 & 11.5 \\
\hline \multirow{4}{*}{ Education level } & $\leq$ Middle school & 2 & 0.5 \\
\hline & High school & 67 & 16.1 \\
\hline & College/University & 273 & 65.6 \\
\hline & Graduate school & 74 & 17.8 \\
\hline \multirow{7}{*}{ Living location } & Seoul* & 177 & 42.5 \\
\hline & Gyeonggi/Incheon* & 193 & 46.4 \\
\hline & Gangwon & 3 & 0.7 \\
\hline & Chungcheong & 15 & 3.6 \\
\hline & Gyeongsang & 12 & 2.9 \\
\hline & Jeolla & 16 & 3.8 \\
\hline & Jeju & 0 & 0.0 \\
\hline
\end{tabular}

\begin{tabular}{|c|c|c|c|}
\hline \multicolumn{4}{|c|}{ Experience of community pharmacy services during the last 1 year } \\
\hline \multirow{4}{*}{$\begin{array}{l}\text { Frequency of visiting } \\
\text { community pharmacy } \\
\text { per month }\end{array}$} & $\leq 1$ & 178 & 42.8 \\
\hline & $2-3$ & 145 & 34.9 \\
\hline & $4-5$ & 47 & 11.3 \\
\hline & $\leq 6$ & 46 & 11.1 \\
\hline \multirow{6}{*}{$\begin{array}{l}\text { Purpose of visiting community } \\
\text { pharmacy (multiple answers } \\
\text { allowed) }\end{array}$} & To fill prescription medication & 358 & 86.1 \\
\hline & $\begin{array}{l}\text { To purchase over-the-counter medications (e.g., digestive medicine, analgesics, and } \\
\text { pain relief patches) }\end{array}$ & 188 & 45.2 \\
\hline & To purchase health functional food (nutritional supplements) & 27 & 6.5 \\
\hline & To purchase para-pharmaceutical products (e.g., adhesive bandages and masks) & 111 & 26.7 \\
\hline & To obtain general health information & 7 & 1.7 \\
\hline & Other & 4 & 0.9 \\
\hline \multirow{3}{*}{$\begin{array}{l}\text { Number of pharmacists among } \\
\text { close acquaintances }\end{array}$} & 0 & 233 & 56.0 \\
\hline & $1-2$ & 165 & 39.7 \\
\hline & $\geq 3$ & 18 & 4.3 \\
\hline \multirow{5}{*}{$\begin{array}{l}\text { Subjectively perceived health } \\
\text { condition }\end{array}$} & Very poor & 1 & 0.2 \\
\hline & Poor & 48 & 11.5 \\
\hline & Fair & 185 & 44.5 \\
\hline & Good & 152 & 36.5 \\
\hline & Very good & 30 & 7.2 \\
\hline \multirow{5}{*}{$\begin{array}{l}\text { Interest in health or health- } \\
\text { related information }\end{array}$} & Not interested at all & 3 & 0.7 \\
\hline & Not interested & 30 & 7.2 \\
\hline & Neutral & 169 & 40.6 \\
\hline & Interested & 166 & 39.9 \\
\hline & Very interested & 48 & 11.5 \\
\hline
\end{tabular}

\footnotetext{
* Classified as a metropolitan region.
} 
Table 2. Trust level in community pharmacists $(\mathrm{N}=416)$

\begin{tabular}{|c|c|c|c|c|c|c|}
\hline \multirow{2}{*}{ Dimension and items } & \multicolumn{5}{|c|}{ Trust level (score; $\min 1-\max 5)(\mathrm{N}, \%)$} & \multirow{2}{*}{ Mean \pm SD } \\
\hline & 1 & 2 & 3 & 4 & 5 & \\
\hline I. Pharmacists' behavior/attitude (7 items) & & & & & & $3.47 \pm 1.05$ \\
\hline Pharmacists listen to me and offer me sufficient respect. & $\begin{array}{c}7 \\
(1.7 \%)\end{array}$ & $\begin{array}{c}35 \\
(8.4 \%)\end{array}$ & $\begin{array}{c}131 \\
(31.5 \%)\end{array}$ & $\begin{array}{c}147 \\
(35.3 \%)\end{array}$ & $\begin{array}{c}96 \\
(23.1 \%)\end{array}$ & $3.70 \pm 0.97$ \\
\hline $\begin{array}{l}\text { Pharmacists are as considerate as possible such that I feel } \\
\text { comfortable. }\end{array}$ & $\begin{array}{c}8 \\
(1.9 \%)\end{array}$ & $\begin{array}{c}59 \\
(14.2 \%)\end{array}$ & $\begin{array}{c}131 \\
(31.5 \%)\end{array}$ & $\begin{array}{c}139 \\
(33.4 \%)\end{array}$ & $\begin{array}{c}79 \\
(19.0 \%)\end{array}$ & $3.53 \pm 1.01$ \\
\hline $\begin{array}{l}\text { Pharmacists choose the best medicine for me instead of } \\
\text { following their personal interests. }\end{array}$ & $\begin{array}{c}20 \\
(4.8 \%)\end{array}$ & $\begin{array}{c}84 \\
(20.2 \%)\end{array}$ & $\begin{array}{c}161 \\
(38.7 \%)\end{array}$ & $\begin{array}{c}106 \\
(25.5 \%)\end{array}$ & $\begin{array}{c}45 \\
(10.8 \%)\end{array}$ & $3.17 \pm 1.03$ \\
\hline Pharmacists do not recommend drugs that I do not need. & $\begin{array}{c}11 \\
(2.6 \%)\end{array}$ & $\begin{array}{c}55 \\
(13.2 \%)\end{array}$ & $\begin{array}{c}124 \\
(29.8 \%)\end{array}$ & $\begin{array}{c}136 \\
(32.7 \%)\end{array}$ & $\begin{array}{c}90 \\
(21.6 \%)\end{array}$ & $3.57 \pm 1.05$ \\
\hline Pharmacists are honest with you if they make a mistake. & $\begin{array}{c}38 \\
(9.1 \%)\end{array}$ & $\begin{array}{c}96 \\
(23.1 \%)\end{array}$ & $\begin{array}{c}156 \\
(37.5 \%)\end{array}$ & $\begin{array}{c}87 \\
(20.9 \%)\end{array}$ & $\begin{array}{c}39 \\
(9.4 \%)\end{array}$ & $2.98 \pm 1.09$ \\
\hline Pharmacists do not conduct illegal or unethical behavior or things. & $\begin{array}{c}8 \\
(1.9 \%)\end{array}$ & $\begin{array}{c}50 \\
(12 \%)\end{array}$ & $\begin{array}{c}136 \\
(32.7 \%)\end{array}$ & $\begin{array}{c}142 \\
(34.1 \%)\end{array}$ & $\begin{array}{c}80 \\
(19.2 \%)\end{array}$ & $3.57 \pm 0.99$ \\
\hline $\begin{array}{l}\text { Pharmacists do not disclose the private medical information of } \\
\text { patients. }\end{array}$ & $\begin{array}{c}5 \\
(1.2 \%)\end{array}$ & $\begin{array}{c}26 \\
(6.3 \%)\end{array}$ & $\begin{array}{c}128 \\
(30.8 \%)\end{array}$ & $\begin{array}{c}153 \\
(36.8 \%)\end{array}$ & $\begin{array}{c}104 \\
(25.0 \%)\end{array}$ & $3.78 \pm 0.93$ \\
\hline II. Pharmacists' technical competence (3 items) & & & & & & $3.67 \pm 0.99$ \\
\hline Pharmacists have adequate expertise in medicine. & $\begin{array}{c}6 \\
(1.4 \%)\end{array}$ & $\begin{array}{c}19 \\
(4.6 \%)\end{array}$ & $\begin{array}{c}95 \\
(22.8 \%)\end{array}$ & $\begin{array}{c}167 \\
(40.1 \%)\end{array}$ & $\begin{array}{c}129 \\
(31.0 \%)\end{array}$ & $3.95 \pm 0.92$ \\
\hline $\begin{array}{l}\text { Pharmacists thoroughly review the appropriateness of prescription } \\
\text { drugs. }\end{array}$ & $\begin{array}{c}13 \\
(3.1 \%)\end{array}$ & $\begin{array}{c}55 \\
(13.2 \%)\end{array}$ & $\begin{array}{c}142 \\
(34.1 \%)\end{array}$ & $\begin{array}{c}134 \\
(32.2 \%)\end{array}$ & $\begin{array}{c}72 \\
(17.3 \%)\end{array}$ & $3.47 \pm 1.02$ \\
\hline Pharmacists provide me with the most appropriate medicine. & $\begin{array}{c}8 \\
(1.9 \%)\end{array}$ & $\begin{array}{c}41 \\
(9.9 \%)\end{array}$ & $\begin{array}{c}140 \\
(33.7 \%)\end{array}$ & $\begin{array}{c}155 \\
(37.3 \%)\end{array}$ & $\begin{array}{c}72 \\
(17.3 \%)\end{array}$ & $3.58 \pm 0.95$ \\
\hline III. Pharmacists' communication skill (3 items) & & & & & & $3.66 \pm 0.99$ \\
\hline Pharmacists explain the medicine in words I can understand. & $\begin{array}{c}3 \\
(0.7 \%)\end{array}$ & $\begin{array}{c}26 \\
(6.3 \%)\end{array}$ & $\begin{array}{c}103 \\
(24.8 \%)\end{array}$ & $\begin{array}{c}185 \\
(44.5 \%)\end{array}$ & $\begin{array}{c}99 \\
(23.8 \%)\end{array}$ & $3.84 \pm 0.88$ \\
\hline $\begin{array}{l}\text { Pharmacists provide me with information I need when I take my } \\
\text { medicine. }\end{array}$ & $\begin{array}{c}9 \\
(2.2 \%)\end{array}$ & $\begin{array}{c}36 \\
(8.7 \%)\end{array}$ & $\begin{array}{c}108 \\
(26 \%)\end{array}$ & $\begin{array}{c}168 \\
(40.4 \%)\end{array}$ & $\begin{array}{c}95 \\
(22.8 \%)\end{array}$ & $3.73 \pm 0.98$ \\
\hline $\begin{array}{l}\text { Pharmacists allow me to ask pharmacy-related questions and } \\
\text { provide sincere answers. }\end{array}$ & $\begin{array}{c}18 \\
(4.3 \%)\end{array}$ & $\begin{array}{c}55 \\
(13.2 \%)\end{array}$ & $\begin{array}{c}147 \\
(35.3 \%)\end{array}$ & $\begin{array}{c}128 \\
(30.8 \%)\end{array}$ & $\begin{array}{c}68 \\
(16.3 \%)\end{array}$ & $3.42 \pm 1.05$ \\
\hline Total sum (13 items) & & & & & & $3.56 \pm 1.02$ \\
\hline Overall trust level & & & & & & $7.16 \pm 1.62$ \\
\hline
\end{tabular}

SD: standard deviation.

years: $45.01 \pm 7.92 ; \geq 50$ years: $47.10 \pm 10.13 ; p=0.02)$ and the average number of pharmacy visit per month $(\leq 1$ visit: $45.18 \pm 8.78$; $\geq 2$ visits: $17.1 \pm 4$ 9.76; $p=0.04$; Table 3 ). The analysis of each of the three trust dimensions revealed that the total scores for pharmacists' behavior/attitude differed significantly depending on the respondents' age $(p=0.01)$, with older groups giving higher points. There were no variables that showed a significant difference in the trust level regarding pharmacists' technical competence dimension. The total scores of communication skills differed significantly based on the age $(p=0.02)$, educational background ( $p=0.01)$, and average number of pharmacy visits per month $(p=0.04)$; the scores were higher in the group aged 50 or above, the group with an education level under high-school graduate, and the group with at least two pharmacy visits per month.

\section{Effect of trust dimensions on overall trust in pharmacists}

The three dimensions of trust (pharmacists' behavior/ attitude, technical competence, and communication skills) significantly influenced the overall trust in pharmacists 


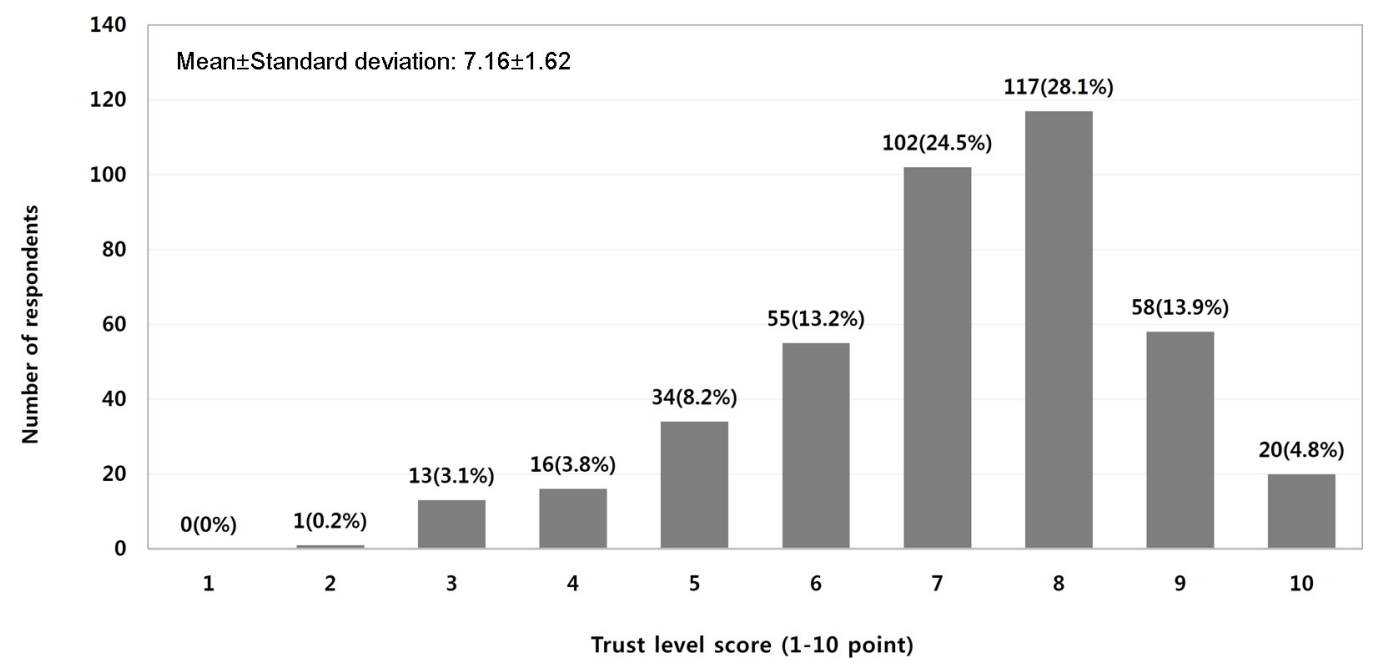

Fig. 1. Overall trust level for pharmacists (total $\mathrm{N}=416$ )

$(p<0.001)$, with pharmacists' behavior/attitude being the most influential factor and communication skills the least influential factor. More specifically, the standardized coefficients beta values were 0.351 for pharmacists' behavior/attitude, 0.289 for pharmacists' technical competence, and 0.185 for pharmacists' communication skills. In the collinearity statistics, the tolerance was $0.356-0.429$, and the variance inflation factors were below 10 , so there was no multicollinearity showing a high correlation between the independent variables. Therefore, each trust component independently affected the overall trust in pharmacists without a high intercorrelation among independent variables.

\section{Discussion}

This study evaluated the level of trust of the public in community pharmacists, which is widely accepted as the most important and decisive factor in the pharmacist-patient relationship. Measuring the general public's trust in community pharmacists in South Korea revealed that the overall trust level in pharmacists averaged 7.16 points (out of a total of 10 points), which was almost at a similar level to the average score of the individual 13 items (3.56 points out of a total of 5 points in average). There are approximately 23,000 community pharmacies that currently provide their services in South Korea. One to two registered pharmacists are working per pharmacy, and individual pharmacists typically dispense an average of 75 drug prescriptions for outpatients per day. ${ }^{13,14)}$ The majority of the respondents $(86.1 \%)$ visited pharmacies for prescription drug-related services. Thus, the results may primarily reflect the individual levels of satisfaction with such services. However, nearly half $(45.2 \%)$ of the respondents visited pharmacies for OTC-related services. Thus, the satisfaction of patients in relation to the purchase of OTC services may have also influenced the results herein.

In this study, the public trust in pharmacists was investigated in the following three dimensions: pharmacists' behavior/ attitude, technical competence, and communication skills. The results underline the following implications. First, pharmacists' behavior and attitude was shown to be the most important factor in building trust with patients. However, of the three dimensions, pharmacists' behavior and attitude scored 3.47, which was lower than technical competence (3.67) and communication skills (3.66) and was the factor most related to decreased levels of trust. In the detailed questions of behavior and attitude, the factors that undermined trust were the pharmacists' unwillingness to acknowledge their mistakes if a mistake was made. This question had a significantly higher response rate of $32.2 \%$ in the $1-2$ point range, with an average score of 2.98 points. The second-lowest scored question, with an average of 3.17 , involved the belief that pharmacists would choose the best medicine for patients rather than following their personal interests. Similarly, Ngorshraches et al. ${ }^{11)}$ conducted a study in Thailand and found an average of 3.52 points for the candid recognition of the pharmacists' mistakes and 3.33 points for the belief that the pharmacist would choose the best medicine over personal profit. Thus, this finding highlights that there is still a lack of trust pertaining to 
Table 3. Trust level in pharmacists by respondent characteristics

\begin{tabular}{|c|c|c|c|c|c|c|c|c|c|c|c|c|c|c|c|c|c|}
\hline \multirow[t]{2}{*}{ Variables } & & \multirow[t]{2}{*}{$\mathrm{N}$} & \multicolumn{3}{|c|}{$\begin{array}{l}\text { Pharmacists' behavior/ } \\
\text { attitude } \\
\text { (max } 35 \text { scores for } \\
7 \text { items) }\end{array}$} & \multicolumn{3}{|c|}{$\begin{array}{l}\text { Pharmacists' technical } \\
\text { competence } \\
\text { (max } 15 \text { scores for } \\
3 \text { items) }\end{array}$} & \multicolumn{3}{|c|}{$\begin{array}{l}\text { Pharmacists' } \\
\text { communication skills } \\
\text { (max } 15 \text { scores for } \\
3 \text { items) }\end{array}$} & \multicolumn{3}{|c|}{$\begin{array}{c}\text { Total sum } \\
\text { (max } 65 \text { scores for } \\
13 \text { items) }\end{array}$} & \multicolumn{3}{|c|}{$\begin{array}{l}\text { Overall trust } \\
(\max 10)\end{array}$} \\
\hline & & & Mean & SD & $p^{*}$ & Mean & SD & $p^{*}$ & Mean & SD & $p^{*}$ & Mean & $\mathrm{SD}$ & $p^{*}$ & Mean & SD & $p^{*}$ \\
\hline Overall & & 416 & 24.31 & 5.40 & & 11.00 & 2.41 & & 10.99 & 2.46 & & 46.30 & 9.39 & & 7.16 & 1.62 & \\
\hline \multirow{2}{*}{ Gender } & Male & 229 & 24.74 & 5.54 & \multirow{2}{*}{0.07} & 10.89 & 2.61 & \multirow{2}{*}{0.29} & 11.07 & 2.51 & \multirow{2}{*}{0.47} & 46.70 & 9.82 & \multirow{2}{*}{0.34} & 7.21 & 1.73 & \multirow{2}{*}{0.4} \\
\hline & Female & 187 & 23.78 & 5.18 & & 11.14 & 2.14 & & 10.89 & 2.40 & & 45.81 & 8.84 & & 7.09 & 1.47 & \\
\hline \multirow{2}{*}{ Age group (years) } & $<50$ & 159 & 23.52 & 4.61 & \multirow{2}{*}{0.01} & 10.86 & 2.13 & \multirow{2}{*}{0.31} & 10.64 & 2.19 & \multirow{2}{*}{0.02} & 45.01 & 7.92 & \multirow{2}{*}{0.02} & 7.01 & 1.40 & \multirow[t]{2}{*}{0.1} \\
\hline & $\geq 50$ & 257 & 24.80 & 5.79 & & 11.09 & 2.58 & & 11.21 & 2.60 & & 47.10 & 10.13 & & 7.25 & 1.74 & \\
\hline \multirow{2}{*}{ Education level } & $\leq$ High school & 69 & 25.25 & 6.19 & \multirow{3}{*}{0.16} & 11.49 & 2.65 & \multirow{3}{*}{0.07} & 11.72 & 2.65 & \multirow{3}{*}{0.01} & 48.46 & 10.72 & \multirow{3}{*}{0.06} & 7.48 & 1.65 & \multirow{3}{*}{0.0} \\
\hline & $\geq$ College/University & 347 & 24.12 & 5.21 & & 10.90 & 2.35 & & 10.84 & 2.40 & & 45.87 & 9.06 & & 7.09 & 1.61 & \\
\hline \multirow{3}{*}{ Living location } & Seoul & 177 & 24.53 & 5.47 & & 11.06 & 2.30 & & 10.97 & 2.38 & & 46.56 & 9.29 & & 7.21 & 1.59 & \\
\hline & Gyeonggi/Incheon & 193 & 24.34 & 5.37 & \multirow[t]{2}{*}{0.41} & 11.07 & 2.52 & \multirow[t]{2}{*}{0.33} & 11.03 & 2.57 & \multirow[t]{2}{*}{0.94} & 46.44 & 9.60 & \multirow[t]{2}{*}{0.50} & 7.16 & 1.63 & 0.64 \\
\hline & Others & 46 & 23.35 & 5.23 & & 10.50 & 2.35 & & 10.91 & 2.36 & & 44.76 & 8.96 & & 6.96 & 1.71 & \\
\hline community pharmacy per month & $\geq 2$ & 238 & 24.75 & 5.53 & 0.05 & 11.19 & 2.43 & 0.07 & 11.20 & 2.58 & 0.04 & 47.14 & 9.76 & 0.04 & 7.22 & 1.70 & 0.30 \\
\hline Number of pharmacists among & 0 & 233 & 24.72 & 5.63 & 008 & 11.18 & 2.48 & 009 & 11.09 & 2.50 & 035 & 46.99 & 9.70 & 000 & 7.20 & 1.62 & 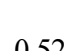 \\
\hline close acquaintances & $\geq 1$ & 183 & 23.79 & 5.06 & 0.00 & 10.78 & 2.32 & 0.03 & 10.86 & 2.41 & 0.00 & 45.43 & 8.93 & 0.03 & 7.10 & 1.61 & 0.02 \\
\hline Pe & Positive & 182 & 24.71 & 5.41 & 0 & 11.08 & 2.42 & 055 & 11.08 & 2.45 & 50 & 46.88 & 9.33 & 27 & 7.26 & 1.61 & 26 \\
\hline Prectived hedul status & Not positive & 234 & 24.00 & 5.37 & 0.10 & 10.94 & 2.41 & $0.5 J$ & 10.92 & 2.48 & 0.50 & 45.85 & 9.44 & 0.21 & 7.08 & 1.62 & 0.20 \\
\hline Interest in health or & Positive & 214 & 24.71 & 5.34 & 017 & 11.10 & 2.41 & $0-41$ & 11.12 & 2.47 & 6 & 46.93 & 9.36 & $016-100$ & 7.24 & 1.65 & 6 \\
\hline health-related information*** & Not positive & 202 & 23.88 & 5.43 & 0.12 & 10.90 & 2.42 & 0.71 & 10.85 & 2.46 & 0.20 & 45.63 & 9.40 & 0.10 & 7.06 & 1.58 & 0.20 \\
\hline
\end{tabular}

** Positive includes "very good" and "good"; not positive includes "fair," "poor," and "very poor."

*** Positive incudes "very interested" and "interested"; not positive includes "neutral," "not very interested," and "not at all interested." 
Table 4. Results of the multiple linear regression analysis

\begin{tabular}{lccccccc}
\hline & \multicolumn{2}{c}{ Unstandardized coefficients } & \multicolumn{2}{c}{ Standardized coefficients } & \multicolumn{2}{c}{ Collinearity statistics } \\
\cline { 2 - 8 } & $\mathrm{B}$ & Standard error & $\beta$ & $\mathrm{t}$ & $p$-value & Tolerance & VIF \\
\hline Intercept & 1.130 & 0.268 & & 4.224 & $<0.001$ & & 2.772 \\
Behavior/attitude & 0.738 & 0.114 & 0.351 & 6.488 & $<0.001$ & 0.361 & 2.808 \\
Technical competence & 0.581 & 0.110 & 0.289 & 5.294 & $<0.001$ & 0.356 & 2.331 \\
Communication skills & 0.364 & 0.098 & 0.185 & 3.720 & $<0.001$ & 0.429 & \\
Adjusted R & 0.561 & & & & & & \\
\hline
\end{tabular}

VIF: variance inflation factors.

the honesty of pharmacists and the belief that pharmacists will make the best choice as experts for patients in Korea. Consequently, policies and training as well as institutional interventions, if necessary, should focus on improving these aspects of community pharmacists.

Second, pharmacists' technical competence and communication skills scored 3.67 points and 3.66 points, respectively. The question graded with less than 3.5 points in the technical competence field was the prescription review (3.47 \pm 1.02$)$. According to a study that analyzed the Korean Health Insurance Claims Database, $44.1 \%$ of elderlies were prescribed more than five drugs in $2010-2011,{ }^{15}$ ) and $80.96 \%$ of the elderlies who received outpatient prescriptions in 20092011 were prescribed potentially inappropriate medication at least once based on the 2012 Beers Criteria. ${ }^{16}$ ) Because Korean society is rapidly aging and the elderly population that suffers from chronic diseases is steadily increasing, the issue of polypharmacy and the risk of potentially inappropriate medication are expected to become more serious, thus further raising the need for pharmacists to review prescriptions. However, the results of this study indicate that the public still lacks trust in this area; therefore, education and policy support for the prescription review competence of pharmacists are required. In the communication skill dimension, the question about pharmacists' sincere responses received less than 3.5 points (3.42 \pm 1.05$)$. Recently, Gregory et al. $(2020)^{17)}$ emphasized that communication-related behaviors and skills in relationships should be used more consistently and effectively to increase patient trust in community pharmacies in Canada; thus, efforts should be made to improve this area. Community pharmacists should also make more attempts to improve their individual communication skills, including interactive communication behaviors and capabilities.

Finally, considering that the higher the frequency of visits was, the higher the trust level was, it seems that trust can be increased through interaction and communication processes between pharmacists and patients. In addition to policy support from pharmacist association groups and public authorities, community pharmacists are required to recognize the lack of trust from patients and aim to improve their behavior/attitude, technical competence, and communication skills to increase public trust. Simultaneously, the importance of building trust with other health professionals, such as physicians and nurses, should not be overlooked or forgotten as increasing information exchange and mutual trust among health professionals is an important part of improving pharmacists' trust. ${ }^{18)}$ Increasing trust in pharmacists is seen as a prerequisite to expanding pharmaceutical services and improving pharmacists' efficiency. Trust in pharmacists is the first driver of patient satisfaction that plays a key role in pharmacist-patient relationships, which ensures the sustainability of future community pharmacies. ${ }^{6)}$ When mutual trust is built, pharmaceutical care services are bound to influence patients' health outcomes more positively, and such experiences can lead to the diversification and expansion of the role of community pharmacists. In Australia, chronic disease management by community pharmacists has been recognized as an appropriate pharmaceutical service owing to careful communication by pharmacists and a comfortable community pharmacy environment and is considered an exemplar of how community pharmacists can expand their roles and contribute to their communities. ${ }^{19)}$

According to the results of the annual trust ratings of professions based on honesty and ethical standards conducted by Gallup in the United States in 2020, the rate of positive (high or very high) ratings ranked first with $89 \%$ for nurses and second with $77 \%$ for physicians, whereas pharmacists ranked fourth with $71 \%$, and the proportion of positive 
evaluations ( 7 points or more, equivalent to high or very high) was the same as with the findings of our study. ${ }^{20)}$ Given that pharmacists are ranked fourth among healthcare professionals (Gallup, 2020) and given the unsatisfactory level of trust toward community pharmacists observed in the current study, additional efforts should be exerted for pharmacists to gain public trust. Several studies have indicated differences in the level of trust in pharmacists. In Taiwan, Chen et al. (2012) showed that only $33.2 \%$ of the public respondents trusted community pharmacists, whereas older people tended to evaluate trust in pharmacists in a more positive manner, similar to the results herein. ${ }^{21)}$ In Kuwait, Awad et al. (2017) revealed that $58.9 \%$ of the respondents trusted pharmacists and $59.6 \%$ were satisfied with pharmacy services. ${ }^{22)}$ Trust in community pharmacists was 3.7 points, which is slightly higher than the result of our study in Korea (i.e., 3.58 points). It is not appropriate to draw a conclusion by simply comparing the results between Korea and other countries because each country has a different economic level and healthcare system as well as different pharmacist roles and social expectations. However, endeavors to narrow the gap between the current trust level and people's expectations must be continued in all countries, and studies that consistently and regularly assess the public's trust in community pharmacists should be conducted.

This study has the following limitations. First, the sample does not fully represent the overall Korean population because the subjects were recruited using a convenient sampling method. The proportions of highly educated people and residents in the Seoul/metropolitan area herein were higher compared to the total population distribution. However, as approximately $50 \%$ of the total 23,000 pharmacies are concentrated in the Seoul/metropolitan area, the residential area of respondents is not expected to have a significant impact on the representativeness of this study. The trust level differed depending on the respondents' characteristics; an education level of high school or less showed a relatively higher trust in pharmacists. Second, the trust scale used herein was developed through literature reviews, experts' interviews, and mutual discussions among researchers, but its reliability was not fully validated. Third, the difference in the number of questions per dimension may lead to a bias in measuring the effect of the dimensions of trust on the overall trust in pharmacists. Therefore, further study using validated and more balanced scales is necessary, and a consistent evaluation on community pharmacists using more reliable and sophisticated trust scales should be followed. Fourth, this study is the first in Korea to investigate the overall trust of community pharmacists, and different pharmacist roles depending on the pharmacy's geographical location or management strategy were not accurately reflected. In the future, it is necessary to compare the trust level according to pharmacy characteristics (e.g., dispensing-oriented pharmacies such as Munjeon Pharmacy or pharmacy on the floor and OTC drug salesoriented pharmacies).

\section{Conclusions}

This study evaluated and presented the current trust level in community pharmacists in South Korea. Since pharmacists' behaviors and attitudes were found to have the greatest impact on public trust, pharmacists need to strive for trusted behaviors and attitudes and continue to make efforts for improving the quality of professional services that meet the expectations of the people.

\section{Conflict of interest}

The authors declare that there is no conflict of interest.

\section{References}

1. Lynch TJ, Wolfson DB, Baron RJ. A trust initiative in health care: why and why now? Acad Med 2019;94(4):463-5.

2. Hall MA, Dugan E, Zheng B, Mishra AK. Trust in physicians and medical institutions: what is it, can it be measured, and does it matter? Milbank Q 2001;79(4):613-39.

3. Mechanic D. Changing medical organization and the erosion of trust. Milbank Q 1996;74(2):171-89.

4. Hindi AMK, Schafheutle EI, Jacobs S. Community pharmacy integration within the primary care pathway for people with longterm conditions: a focus group study of patients', pharmacists' and GPs' experiences and expectations. BMC Fam Pract 2019;20(1):26.

5. Ilardo ML, Speciale A. The community pharmacist: perceived barriers and patient-centered care communication. Int J Environ Res Public Health 2020;17(2):536.

6. Castaldo S, Grosso M, Mallarini E, Rindone M. The missing path to gain customers loyalty in pharmacy retail: the role of the store in developing satisfaction and trust. Res Social Adm Pharm 2016;12(5):699-712.

7. Moorman C, Deshpandé R, Zaltman G. Factors affecting trust in market research relationships. J Mark 1993;57(1):81-101.

8. Beney J, Bero LA, Bond C. Expanding the roles of outpatient pharmacists: effects on health services utilisation, costs, and patient outcomes. Cochrane Database Syst Rev 2000;(3):CD000336.

9. Hindi AMK, Schafheutle EI, Jacobs S. Patient and public 
perspectives of community pharmacies in the United Kingdom: a systematic review. Health Expect 2018;21(2):409-28.

10. Gregory PAM, Austin Z. Understanding the psychology of trust between patients and their community pharmacists. Can Pharm J (Ott) 2021;154(2):120-8.

11. Ngorsuraches S, Lerkiatbundit S, Li SC, Treesak C, Sirithorn R, Korwiwattanakarn M. Development and validation of the patient trust in community pharmacists (TRUST-Ph) scale: results from a study conducted in Thailand. Res Social Adm Pharm 2008;4:27283 .

12. Zhang XH, Jin J, Ngorsuraches S, Li SC. Development and validation of a scale to measure patients' trust in pharmacists in Singapore. Patient Prefer Adherence 2009;3:1-7.

13. National Information Society Agency. Pharmacy information. Available from https://www.localdata.go.kr/datafile/each/01_01 06_P_CSV.zip. Accessed July 1, 2021.

14. Health Insurance Review and Assessment Service. Major statistics on medical expenses. Available from https://www.hira.or.kr/bbs Dummy.do?pgmid=HIRAA020045030000\&brdScnBltNo=4\&brd $\mathrm{BltNo}=2411$ \&pageIndex $=1$. Accessed July 1, 2021.

15. Park HY, Ryu HN, Shim MK, Sohn HS, Kwon JW. Prescribed drugs and polypharmacy in healthcare service users in South Korea: an analysis based on National Health Insurance Claims data. Int J Clin
Pharmacol Ther 2016;54(5):369-77.

16. Nam YS, Han JS, Kim JY, Bae WK, Lee K. Prescription of potentially inappropriate medication in Korean older adults based on 2012 Beers Criteria: a cross-sectional population based study. BMC Geriatr 2016;16:118.

17. Gregory PA, Austin Z. How do patients develop trust in community pharmacists? Res Social Adm Pharm 2021;17(5):911-20.

18. Lee IH, Rhie SJ, Je NK, et al. Perceived needs of pharmaceutical care services among healthcare professionals in South Korea: a qualitative study. Int J Clin Pharm 2016;38(5):1219-29.

19. Bajorek BV, LeMay KS, Magin PJ, Roberts C, Krass I, Armour CL. Management of hypertension in an Australian community pharmacy setting-patients' beliefs and perspectives. Int $\mathrm{J}$ Pharm Pract 2017;25(4):263-73

20. Gallup 2020. America trusts the most trusted profession more than ever. Jan 1, 2021. Available from https://dailynurse.com/gallup2020-america-trusts-the-most-trusted-profession-more-than-ever/. Accessed February 20, 2021.

21. Chen YC, Tarn YH, Kreling DH. Public views of community pharmacists in Taiwan. Int J Pharm Pract 2012;20(3):203-6.

22. Awad AI, Al-Rasheedi A, Lemay J. Public perceptions, expectations, and views of community pharmacy practice in Kuwait. Med Princ Pract 2017;26(5):438-46.

\section{Author's information}

Sung Won Yoon: Undergraduate Hye Sung Han: Graduate student Hae-Young Park: Post Doc Hyun Soon Sohn: Professor 